\title{
CLASSIFICATION AND OCCURRENCE OF DEFECTIVE ACTS IN RESIDENTIAL CONSTRUCTION PROJECTS
}

\author{
Hamad A. ALJASSMI ${ }^{\mathrm{a}}$, Sangwon HAN ${ }^{\mathrm{b}}$ \\ ${ }^{a}$ School of Civil and Environmental Engineering, University of New South Wales, Sydney, Australia \\ ${ }^{b}$ Department of Architectural Engineering, University of Seoul, Seoul, Korea
}

Received 09 Aug 2011; accepted 02 Mar 2012

\begin{abstract}
Defects can have a significant impact on construction performance. Numerous studies have attempted to identify their root causes, contending that the prevention of defects could be achieved by eliminating the root causes. Yet, their direct causes also need to be considered in order to identify the sequence of events leading to defects. This study aims to classify the defective acts that are directly linked to the occurrence of a defect, in order to provide insights about the nature and the impact of different types of direct causes. The study involves investigation into 272 defects from 81 disputes that occurred in the Dubai residential construction industry in 2009. Results from this study reveal that the majority of construction defects are driven by a violation of practices or workers' lack of skill and competence. While it is difficult to prevent deliberate violations, increased effort toward growing skills and competencies would be effective in reducing defects, and therefore improving construction performance. Also, classification of defective acts is envisioned as a platform toward a more thorough causal tracking of construction defects, facilitating the identification of latent conditions resulting in defects.
\end{abstract}

Keywords: defect, rework, failure, error.

Reference to this paper should be made as follows: Aljassmi, H. A.; Han, S. 2014. Classification and occurrence of defective acts in residential construction projects, Journal of Civil Engineering and Management 20(2): 175-185. http://dx.doi.org/10.3846/13923730.2013.801885

\section{Introduction}

In construction, a defect is "a failing or shortcoming in the function, performance, statutory or user requirements of a building, and might manifest itself within the structure, fabric, services or other facilities of the affected building" (Watt 1999). It does not exclusively refer to a shortcoming being at the extent of a catastrophic failure (e.g. crack) but also includes undesired non-conformance with principles or requirements, which may or may not result in rework.

Defects can have a significant impact on construction performance. They may lead to rework (Burati et al. 1992; Willis, T. H., Willis, W. D. 1996; Love et al. 2009), schedule delays, cost overruns (Chan, Kumaraswamy 1997) or claims and disputes (Love et al. 2010b). Moreover, they often create unsafe environments (Ortega, Bisgaard 2000), suppress workers' morale, and may decrease their productivity (Love et al. 2010d).

The construction industry development board in Singapore (CIDB 1989) estimated that contractors spend $5 \%$ to $10 \%$ of the total project cost rectifying defects. Josephson and Hammarlund (1999) also reported that the cost of defects in residential, industrial and commercial construction projects ranges from $2 \%$ to $6 \%$ of their total contract value. Recently, Mills et al. (2009) claimed that defect rectifications in the residential construction industry cost $4 \%$ of the contract value. These figures include only the direct costs of defects. However, it has been found that the resulting indirect costs could escalate to up to six times those aforementioned (Love 2002).

Any attempt to eliminate defects should be accompanied by identification and classification of their various causes (Cooper 1993; Rodrigues, Bowers 1996; Love et al. 2009). When the causes of defects are systematically identified and classified, project practitioners would have a platform to prevent the occurrence of defects as well as detect them as early as possible. Based on this recognition, identification and elimination of the causes of defects has been a significant concern among construction researchers and practitioners.

There have been several attempts to identify the root causes of construction defects (e.g. Burati et al. 1992; Chan, Kumaraswamy 1997; Josephson, Hammarlund 1999; Busby, Hughes 2004; Love et al. 2008, 2009, 2010a). However, there is yet a need to develop a comprehensive framework in order to thoroughly understand complex causal relationships resulting in construction defects. To address this deficiency, this paper analyzes defective acts, of which a greater understanding is required to better explain the causalities between construction defects and their root causes. 


\section{Research objective}

A cause is a proven reason for the existence of an undesired result (e.g. a defect) (Josephson, Hammarlund 1999). Literature distinguishes between 'root causes' (also called 'latent conditions' or 'pathogens') and 'direct causes', where the former describes the most fundamental reasons for defects and failures, while the latter can primarily be attributed to individuals who are influenced by these conditions (Josephson, Hammarlund 1999). Based on this principle, Reason (1990) introduced the Swiss Cheese Model for identifying the causes of accidents. The Swiss Cheese Model suggests that most accidents can be traced to one or more of the four descending levels (organizational influences, unsafe supervision, preconditions for unsafe acts and the unsafe acts) as shown in Figure 1a. The unsafe acts level, which lies in direct contact with an accident, represents individuals' erroneous practices that are formalized either in terms of human errors or violations. As such, the term 'defective acts' is adopted herein to represent such individualistic direct causes, which stand as the final barrier between root causes and the occurrence of a defect (Fig. 1b).

It has been argued that any problem in construction can be prevented if its root cause is eliminated (Josephson, Hammarlund 1999; Busby, Hughes 2004; Love et al. 2009, 2010b), unless individuals deliberately violate (Sommerville 2007). Accordingly, there have been considerable efforts to identify the root causes of construction problems (e.g. Burati et al. 1992; Chan, Kumaraswamy 1997; Josephson, Hammarlund 1999; Busby, Hughes 2004; Love et al. 2008, 2009, 2010a).

It is true that merely focusing on the back-end root causes (inputs) against the front-end results (outputs) can, to a large extent, detect the causes that could be removed to eliminate construction problems. However, the mechanics and complex correlations acting among these variables and those lying on the sequence of events between them are not well understood. As shown in Figure 1c, if we simply focus on identification of a root cause in order to prevent an identified defect, we may conclude that schedule pressure is the root cause of the slab deflection and that schedule pressure should have been reduced to avoid the slab deflection. However, it is unclear how schedule pressure resulted in the slab deflection. More in-depth examination between the defect and its root cause is required for a thorough understanding of mechanic of defect generation (e.g. the habit of omitting design checks due to schedule pressure introduced production of a faulty design document, which then resulted in adopting such misguiding instruction during the execution of the slab).

As exemplified in Figure 1, design faults can materialize through defective acts during construction and/or their negative impacts are magnified by construction defects. Even under perfect design documents, a defect may occur due to incorrect execution. This is among the error types addressed by Reason (1990) where intentions are correct but execution is incorrect (i.e. violation). Atkinson (1998) claims that correction on the root causes will only have a partial, or no effect on the elimination of deliberate violations. Accordingly, in order to guarantee encompassing all variables contributing to a defect, it is necessary to analyse the direct causes of a defect because any latent condition (i.e. root causes) in all cases must pass through this final barrier (i.e. direct cause) before a defect manifests.

The resulting aim of this study is to provide means for a more thorough analysis of defect causes by identifying defective acts in direct contact with defects. Specifically, a set of defects are classified based on their direct causes (i.e. defective acts) and then each type of defective act is analysed. These classifications are envisioned as a platform toward more thorough causal tracking of construction defects, facilitating further studies to identify latent conditions that result in defects.

Several latent conditions inherent in construction projects make them highly prone to defects. The most identifiable condition is the repetitive economic or schedule pressures imposed on firms and individuals (Love et al. 2009). These pressures may be imposed by clients who themselves are driven by several reasons such as

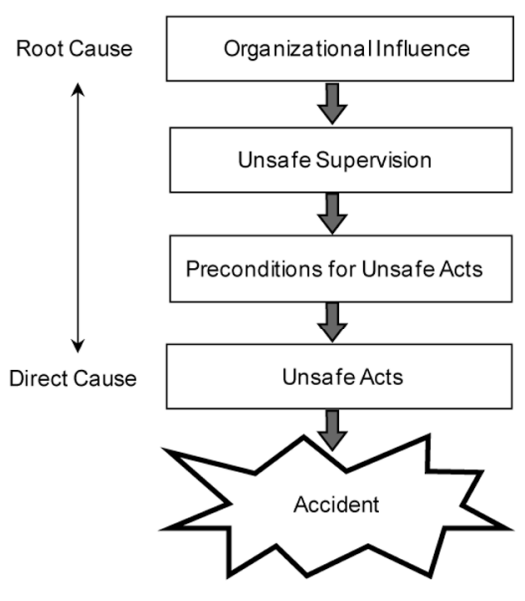

(a) SafetyContext (Reason 1990)

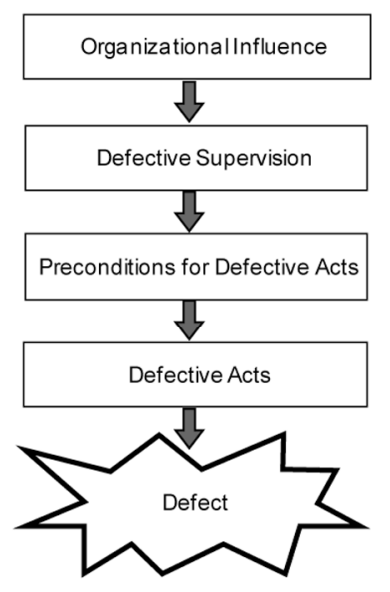

(b) Quality Context

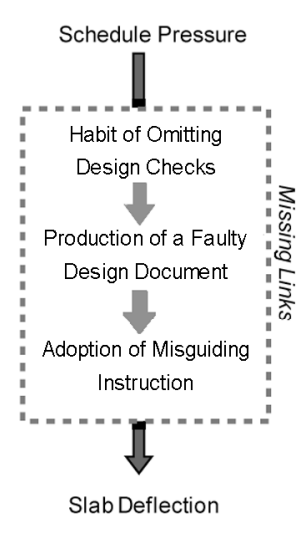

(c) Construction Example

Fig. 1. The missing link between root causes and defects (augmented from Reason (1990)) 
increasing capital costs, increasing expectations of shareholders towards return on investment, increasing competition in markets, environmental concerns and the increasing population which requires physical infrastructure (Love et al. 2009). Other pressures imposed on construction firms may include the scarcity of resources such as skilled labour (Love et al. 2010d) and liquidity.

\section{Root causes of defects: latent conditions}

Regardless of the source of pressure on firms and individuals, the result is a turbulent environment, which leads to more defects. For instance, Tilley and McFallen (2000) showed that where clients demanded earlier completion of projects, designers often produced erroneous contract documentation. Moreover, Love et al. (2009) suggested that it has become a norm for designers to eschew audits, checks, verifications and reviews due to financial and time pressures imposed by clients. Today, it is not abnormal for firms to commence construction with incomplete design documentation in order to accelerate the construction schedule (Waldron 2006). Such shortcuts increase the probability that defects will occur at the execution stage.

The complex nature of construction projects also increases their propensity to incur defects. Current project management norms obviate conventional top-down command and leadership hierarchies. Consequently, complex and overlapping-task-oriented systems are adopted to ensure projects are delivered within optimized schedules (Love et al. 2010d). The drawback is, however, that decision-makers and managers have less control upon information-flows and upon consequences of people's actions (Aram, Noble 1999). Project elements become complexly interdependent so that a decision made on one part of the project triggers events that may be unpredictable in other parts of it (Perrow 1984; Williams 2002). Moreover, individuals are often compelled to perform their tasks (or at least part thereof) on the basis of tentative information (Love et al. 2009). Project goals and objectives may also be unclear or missing in many cases (Williams 2002). All of these latent conditions make construction projects particularly prone to defects.

\section{Direct causes of defects: defective acts}

Describing the turbulent environment in which defects have occurred is not sufficient to provide insights to their actual mechanics. Rather, more detailed observations of project systems and people's behaviour are needed. Reason (1990) stated that direct causes of a problem (e.g. defect or accident) can be classified into either errors or violations. Both errors and violations are considered 'acts' that generate defects. In parallel, defects are considered 'outcomes' of these errors and violations.

\subsection{Errors}

An error is an act "in which the outcome was appreciably worse than the expectation, could not be put down entirely to chance or circumstances, and involved some element of surprise" (Busby, Hughes 2004). Human errors in particular occur due to physiological or cognitive limitations (Love et al. 2010c). They involve a sort of a deviation: whether from an intended course of action; from a route of actions planned toward a desired goal; or a deviation from the "right" behaviour at work (Busby, Hughes 2004).

Numerous studies have considered the nature of human errors as well as their types and causes. Rasmussen (1983) for example assorted different kinds of human errors, where he argues that each is performed at a different level: skill-based, knowledge-based and rule-based. These assortments are based on intention adjustments against execution. At the skill-based level, slips and lapses occur where the intention is correct but the execution is wrong. At the knowledge-based level, which Kletz (1985) refers to as mismatches, intentions are rather wrong but executions are correct. Skill-based errors involve behavior where work is routine and relatively automatic; whereas knowledge-based errors involve behavior that requires some thought and consciousness. The third kind of human error is rule-based, where individuals execute tasks on the basis of rules. The rule-based error occurs when they apply a rule where it is not applicable.

Love et al. (2009) summarizes the reasons for human errors as follows:

- Mistakes - where errors occur as a result of ignoring the correct task or the correct method. According to Rasmussen (1983), a mistake is either rule-based or knowledge-based. This happens usually when individuals encounter a novel situation that involves thoughtful ideas lying beyond the range of their learnt problem solving routines;

- Slips and lapses of attention - where errors occur as a result of forgetfulness, habit, or similar psychological issues. This type of error is purely encountered at the level of execution, and generally occurs where tasks are routine and the surroundings are familiar.

\subsection{Violation}

On contrary to errors, which are unintentionally made due to psychological or cognitive limitations, violations are intentionally taken (Reason 1990; Van-Dyck et al. 2005). They are acts resulting in undesired outcomes (i.e. defects) in which "individuals decide not to carry out a task or not to carry it out according to instruction or expectations" (Love et al. 2010c). They differ from errors in a sense that errors can be explained by physiological, cognitive or informational problems, but violations are found in a regulated social context (Reason 1995).

Errors can be reduced through removing latent conditions that hinder the delivery of necessary information (Reason 1995) or skill within a workforce. On the other hand, elimination of deliberate violations is not necessarily guaranteed through such preventive strategies since they may not be the result of a root cause (Sommerville 2007; Atkinson 1998). This is a key reason to consider direct causes as well as root causes of defects in construction.

Violations may occur due to their inherence within the organizational culture setting (Van-Dyck et al. 2005), 
due to individualistic motivational problems such as low morale or poor supervision; or simply due to fleeting perceptions of opportunities to improve operational efficiency or productivity (Love et al. 2009).

Regardless the differences in qualities and triggers involved behind these errors and violations, the common aspect among them is that they stand as the final barrier between the root causes and the occurrence of a defect. It has been argued that an ideal approach to defect prevention is to view these defective acts (i.e. errors and violations) as a symptom of underlying problems, and in this way they become sources of information to understand root causes or latent conditions (Busby 2001; Homsma et al. 2007; Love et al. 2009). Based on this recognition, this paper aims to develop an enhanced understanding of defective acts, which will act as a platform toward more comprehensive sequential tracking of factors contributing to construction defects.

\section{Data collection}

Any attempt to prevent defects shall be driven by apprehending their archetypal nature. Establishing the appropriate methods and techniques for understanding defective acts is necessary for project managers to implement strategies for defect containment (enhancing defect discovery and minimizing its adverse consequences) and defect reduction (limiting its occurrence) (Love et al. 2009).

For this, it is imperative to first classify defective acts because established generic categories are beneficial in a sense that they provide a structured pattern of assessing vulnerability (Busby, Hughes 2004); and practically speaking, these are deemed useful for the assessment of potential risks (Love et al. 2009). These could, for example, provide project practitioners with a checklist alerting for potential defect occurrence prior to construction, based on certain underlying conditions (Love et al. 2009).

For the purposes of classifying defective acts, we elect a database obtained from Dubai Municipality (a government authority which controls the local construction industry). The database was selected because of its richness in holding a significant number of defects that encompass a variety of determinants, allowing development of a reliable set of defective act classifications.

From the database, a sample of 272 defects from 81 disputes that occurred in 2009 is studied. These disputes typically involve three main parties: the client, the contractor and the consultant (i.e. designer/engineer) and are often triggered by multiple construction defects (ranging from 1 to 12 in our dataset). Information regarding each defect was carefully derived from records documented by observers of each dispute case. The information includes: the plaintiff's complaint letter; reports from the municipality's engineer (who usually conducts multiple site visits to investigate defects and monitor their rectification); reports from both the contractors and the consultant (explaining the cause of defects and the rectification plan); as well as other technical and non-technical correspondence between the stakeholders, regarding defect triggers and their rectification progress. Thus, the database provides significant insights to classify defects based on their direct causes (i.e. defective acts).

\section{Research methodology}

The development of categories consisted of two interrelated procedures: data clustering (creating classification categories) and classification allocation (assigning each defective act case to its right classification). According to Hammersley and Atkinson (1995) categories may come from three derivations: relevant literature; participants' interaction with the data (i.e. as in grounded theory); or participants' prior experience. In this research, data clustering was primarily based upon literature synthesis (summarized in Table 1). A holistic view of documents written by observers including municipality engineers in the dataset, was also incorporated, which is supported by the researchers' site experience. Based on these methods, several refinements were made to the classifications throughout the analysis, resulting in the identification of nine defective acts clusters outlined below:

- Poor workmanship: Constructing with a degree of skill that is considered poor by the stakeholders;

- Impaired material usage: Using, or retaining the use of, a material that is by any means not suitable for the constructed element;

- Task sequence omission: Omitting a primary or a supplementary step in a task, which is required to accomplish the job appropriately;

-Deviation from an intended dimension: Failing to comply with the exactly right dimension due to inaccuracy;

-Instruction contravention: Disregarding a detail or a recommendation (e.g. drawing) that is clearly provided by an instructor (e.g. designer);

- Professional principles/conventions noncompliance: Performing the job in a manner that is not keeping with professionally established practices;

-Official rule noncompliance: Adopting work practices not complying with the state's rules and regulations;

-Items interdependence disregard: Performing a task in a manner that negatively affects another interrelated task;

-Adoption of misguiding instruction: Performing the job on the basis of a misleading instruction (e.g. drawing).

Each category is discussed in further detail in the following sections with representative examples in the following section.

After aggregating literature to form these categories, clusters were refined on the basis of observations documented by stakeholders involved in disputes. Each of the defect incidents were allocated to a category. The advantage of using formerly documented observations, as opposed to interviews, is that it avoids a discrepancy between what people claim they have done or will do, and what they actually did (Robson 1993). In scientific 
Table 1. Literature syntheses in which defective act classifications are developed

\begin{tabular}{|c|c|c|c|c|c|c|c|c|c|}
\hline & 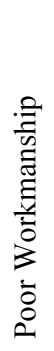 & 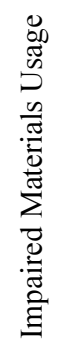 & 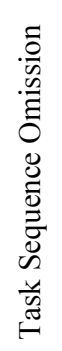 & 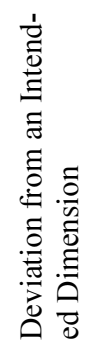 & 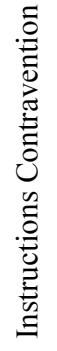 & 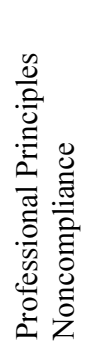 & 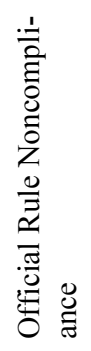 & 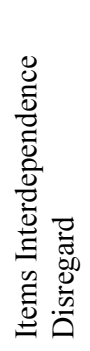 & 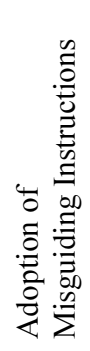 \\
\hline Crosby (1984) & & & & & $\bullet$ & & & & \\
\hline Coles (1990) & & & & & & $\bullet$ & & & \\
\hline Hammarlund et al. (1990) & $\bullet$ & & & & & & & & \\
\hline Hammarlund and Josephson (1991) & $\bullet$ & & & & & & & & \\
\hline Ashford (1992) & & & & & $\bullet$ & & & & \\
\hline Abdul-Rahman (1995) & & & & & $\bullet$ & & & & \\
\hline Assaf et al. (1995) & & $\bullet$ & & $\bullet$ & $\bullet$ & $\bullet$ & & & $\bullet$ \\
\hline Gidado (1996) & & & & & & & & $\bullet$ & \\
\hline T. H. Willis and W. D. Willis (1996) & & & $\bullet$ & & & & & & \\
\hline Pressman (1997) & & & & & & $\bullet$ & & & \\
\hline Reason (1998) & & & • & & & & & & \\
\hline Josephson and Hammarlund (1999) & & $\bullet$ & & & & & & & \\
\hline Watt (1999) & & & & & & $\bullet$ & $\bullet$ & & \\
\hline Love (2002) & $\bullet$ & & & & & & & & \\
\hline Winch (2003) & & & & & & & & $\bullet$ & \\
\hline Kärnä (2004) & & & & & $\bullet$ & & & & \\
\hline Love and Josephson (2004) & $\bullet$ & $\bullet$ & & & & & & & $\bullet$ \\
\hline Pandey et al. (2008) & & $\bullet$ & & & & & & & \\
\hline Alsadey et al. (2010) & $\bullet$ & & & & & & & & \\
\hline Bankvall et al. (2010) & & & & & & & & $\bullet$ & \\
\hline Georgiou (2010) & $\bullet$ & & & & & & & & \\
\hline
\end{tabular}

terms, observation is "the recording of behavioural patterns of people, objects and events in a systematic manner to obtain information about the phenomenon" (Malhotra et al. 2002). Observational research is either structured or unstructured. Structured observation is considered to be more reliable since it is based on specific details of what observations to be made and how measurements should be recorded (Robson 1993). For this, a protocol was required to impose a structure for classifying defective acts in accordance with the developed clusters. Monitoring of the comprehensiveness of classifications was also required, so that they neither overlap nor omit any defective act with regards to their resulting defect. To satisfy these requirements, a flow chart was developed based on the researchers' previous site experiences (Fig. 2).

A similar approach was introduced by Abdelhamid and Everett (2000), who tailored a flow chart representing the synthesis of previous literatures. The flow chart consisted of a series of questions and possible answers, to be used to assist an investigator in determining the causes of construction accidents. The flow chart developed in this study aims to provide a systemic method for classifying defective acts, as well as refining the set of categories when required. It was also essential to reduce researchers' analytical bias and provide consistent categorization of defective acts. Answering the flow chart questions (with 'Yes' or 'No', see Table 2), and using the detailed description of each type of defective act ensures that the set rules are followed, and categories cannot overlap. The sequence of questions was purposefully formulated to avoid possible confusion between classifications. Placing particular types of defective acts before others in the flowchart sequence ensures that the classifications are assigned consistently and accurately without being confused with other categories. For example, the act of poor workmanship could be confused with the deviation from an intended dimension. Since deviation from an intended dimension is a subset of poor workmanship, the former is placed higher in the flow chart, so that remaining defective acts fall into the latter, broader category.

\section{Data analysis}

Using the flow chart, 272 defects were classified, and then occurrence of each defective act type was identified. 


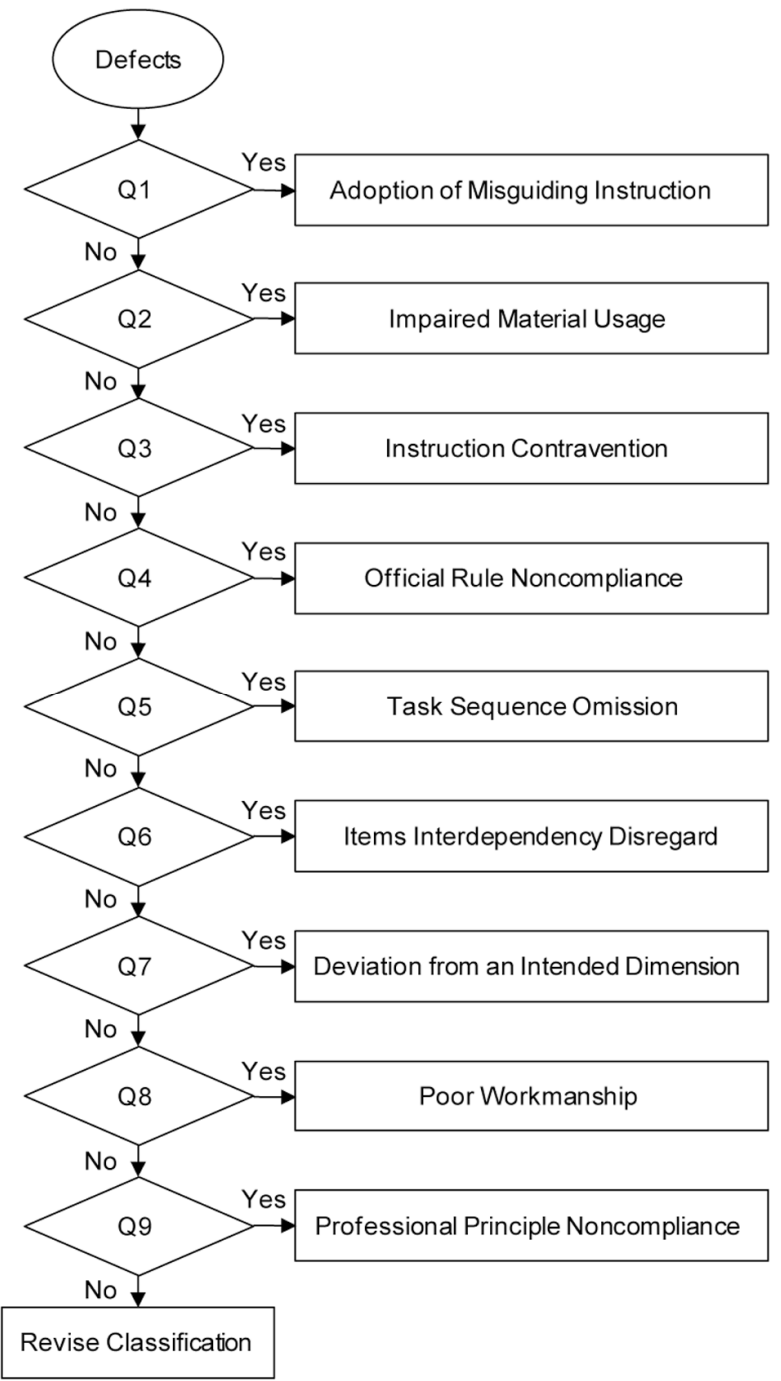

Fig. 2. A flow chart for classifying defective acts

Table 2. Questions for classifying defective acts

\begin{tabular}{c|l}
\hline No. & \multicolumn{1}{|c}{ Question } \\
\hline Q1 & $\begin{array}{l}\text { Did the builder perform the job on the basis of a mis- } \\
\text { leading instruction? }\end{array}$ \\
\hline Q2 & $\begin{array}{l}\text { Did the builder use or retain the use of an impaired } \\
\text { material? }\end{array}$ \\
\hline Q3 & $\begin{array}{l}\text { Did the builder disregard a detail or a recommendation } \\
\text { (other than rules, regulations and general quality } \\
\text { standards) that have been clearly provided by an in- } \\
\text { structor? }\end{array}$ \\
\hline Q4 & $\begin{array}{l}\text { Did the builder perform the job and however, it in- } \\
\text { volved an aspect which does not comply with the } \\
\text { state's rules and regulations? }\end{array}$ \\
\hline Q5 & $\begin{array}{l}\text { Did the builder omit and of the primary or supplemen- } \\
\text { tary steps that are required to accomplish the job ap- } \\
\text { propriately? }\end{array}$ \\
\hline Q6 & $\begin{array}{l}\text { Did the builder execute any of these steps executed in } \\
\text { a manner that have had a negative effect in another? }\end{array}$ \\
\hline Q7 & $\begin{array}{l}\text { Did the builder intend to perform the job in compli- } \\
\text { ance with instruction but the execution deviated from } \\
\text { the right dimension due to inaccuracy? }\end{array}$ \\
\hline Q8 & $\begin{array}{l}\text { Did the builder construct with a degree of skill that is } \\
\text { considered poor by any of the stakeholders? }\end{array}$ \\
\hline Q9 & $\begin{array}{l}\text { Did the builder perform the job in a manner that is } \\
\text { distinct from the profession's established practices? }\end{array}$ \\
\hline
\end{tabular}

\subsection{Poor workmanship (20\%)}

Love and Josephson (2004) define workmanship errors as those that "can be traced back to the main contractor's workers, normally carpenters and concrete workers". Thus, these are strictly concerned with the quality of skills held by workers employed in performing a certain task (skill-based errors). Georgiou (2010) reported that in three separate studies poor workmanship was found to be a predominant cause of house defects in Australia, ranging between $38 \%$ and $77 \%$ of each sample. Alsadey et al. (2010) reported that over one-third of the defects in the Libyan construction industry were caused by poor workmanship. Unsurprisingly, results of this study also indicate that poor workmanship is the predominant category, accounting for $20 \%$ of defects in Dubai. Common examples of defects resulting from poor workmanship include: uneven plasterboard finish, unaligned floor surfaces, unaligned steel reinforcement bars, voids remaining between flooring tiles, and inappropriate attachment of an object to another.

\subsection{Impaired material usage (20\%)}

The use of damaged, unfitting or unsuitable materials undermines the functionality of constructed elements, leading to defects (Assaf et al. 1995). Josephson and Hammarlund (1999) revealed that approximately $20 \%$ of defect costs originated from impaired materials. Likewise, Pandey et al. (2008) discuss the initiatives of housing safety in Indonesia, Nepal, Pakistan and Turkey; and they report that in each of these countries, poor construction material was found to be the major factor for weaknesses in houses. Similarly, Dubai's residential construction industry suffers from such defects, ranking second in terms of their occurrence. The use of impaired materials may occur due to the delivery of damaged materials and failure of site personnel to detect the impairment (knowledge-based errors) (Love, Josephson 2004), or due to misjudgements of contractors upon the selection of materials (rule-based or knowledge-based errors). For example, numerous cases in the database show that contractors were unaware of the appropriate plasterboard mixture. However, in other cases, impaired material usage occurred due to contractors' intention to save costs through utilizing lower quality materials (violations). Also, in cases where materials are formed in situ such as concrete, defects were found to occur during the mixing process, by mixing incorrect proportions. In other cases builders have used the correct material, but mistreatment led to damage, which was not sufficiently rectified during construction. A typical example found in the dataset is the use of reinforcing steel bars, which rust due to extended exposure. Regardless of the factors causing damage to materials, the usage of inappropriate materials imposes negative impacts on construction projects. Other examples of this defective act category include using corroded post-tension rods, or using broken or crushed fittings (e.g. toilet fittings, kitchen fittings, etc.). 


\subsection{Task sequence omission (15\%)}

According to Reason (1998), the most common human error is the failure to carry out compulsory steps in the execution of a task. Omission errors were found to account for $38 \%$ of the total rework costs (Willis, T. H., Willis, W. D. 1996). The data analysis results show that these failures constantly recur within construction projects in Dubai (15\% of the encountered failures). They are generally triggered by violations, and in some cases by knowledge-based errors. An example of a defect caused by task sequence omission is a yard interlock becoming unlevelled because the initial task of compacting the earth was omitted. In some cases, contractors were unaware of whether the neglected procedure was necessary or not. This phenomenon appears, for example, when electricity ducts are unwittingly left uncovered allowing rainwater to infiltrate. Thus, no matter how minor a task in a given sequence may seem, omitting it can yield unexpected defects in the constructed element. Other examples of task sequence omissions include performing brickwork without filling the block gaps with mortar joints, not cleaning formwork prior to casting, and not curing concrete after casting.

\subsection{Deviation from an intended dimension (13\%)}

Deviations from intended dimensions are a defective act where builders intend to fully comply with the provided construction drawings but fail to meet the exact dimension required (i.e. deviations of the order of centimetres or millimetres). Assaf et al. (1995) refers to these as defects due to inadequate measurements. Although such defects often do not seem highly severe, a handful of cases in Dubai's construction industry have proven that these errors can have fatal consequences. For example, a slight deviation in a column's verticality will escalate to a sharper inclination. Also, a mistake in matching the intended slab thickness will decrease its strength and will then cause it to deflect, or even collapse. The obvious trigger of this defective act is workers' inaccuracy (skillbased error), however it may also be triggered by violation acts on a rare occasion. Further examples of this defective act include exceeding site boundary limits, projection of a column from the footing tie beams, and the alignment angle of a floor slope.

\subsection{Instructions contravention (10\%)}

Instructions are considered to be any sort of information upon which builders are supposed to base execution. They can take different forms such as drawn, vocal or written guidelines, and can vary in scope such as illustrating a major design concept or providing a window dimension. The contravention of these instructions include, for example, neglecting a drawn detail, not adopting the intended design, or placing an element in a position that deviates from that instructed in drawings. No matter the degree of excellence at which such tasks are accomplished, since they do not conform with the instructed requirements, they are considered quality failures (defects) (Crosby 1984; Assaf et al. 1995; Kärnä 2004) that entail rework (Abdul-Rahman 1995; Ashford 1992). Instruction contravention acts primarily originate from violations, though they can also be rule-based errors.

\subsection{Professional principles/conventions noncompliance $(9 \%)$}

Violating principles and/or conventions refers to performing tasks in a manner that is deviate from the profession's established practices. An example of principles violation is digging into a loaded concrete footing for the sake of planting mechanical cables. In an interesting case found in the dataset, the contractor constructed columns without foundations: incorrect in terms of both intention and execution. Project participants including clients, consultants and authorities presume that contractors work in compliance with principles and conventions. Even when courts make judgment on contractors' liability, they do not hold them to a standard of perfection; rather they judge in accordance to professional judgments (Pressman 1997). However, since workers often learn by practice or from their more experienced colleagues, rather than by education or formal training (González 2001, cited in Serpell, Ferrada 2007), there is generally a fluctuant level of professionalism. Thereby, such errors may result from inexperienced or under-qualified staff that lacks the technical knowledge required (Coles 1990; Assaf et al. 1995; Watt 1999).

\subsection{Official rule noncompliance ( $7 \%$ )}

Any construction project in Dubai is subject to periodic investigations by the municipality's engineers to confirm its compliance with the Dubai Municipality's building rules and regulations. Watt (1999) considers failing to comply with these statutory requirements a defect. A traditional philosophy behind enforcing these rules is to standardize the work among construction projects so that accidents and faults are prevented and a higher quality of buildings is achieved throughout the city. Nevertheless, contractors sometimes confuse rules with others and thus unintentionally violate them (rule-based errors). However, the majority of contractors work for their own interest, and violate the rules when they perceive that there is a benefit, or at least no risk, in doing so (violation acts). For instance, in-situ concrete is forbidden in Dubai since it is more difficult to monitor and control concrete strength through this mixing method. Instead, the government allows only pre-casted concrete to be used. The dataset shows examples where concrete strength has been weaker than required because of rule violations and the use of in-situ mixed concrete.

\subsection{Items interdependence disregard (4\%)}

Construction is a highly complex industry, which necessitates coordination between interdependent tasks, parts and units involved (Gidado 1996; Winch 2003; Bankvall et al. 2010). Normally changes in one item affect the state of others. That is, if these interdependencies were disregarded, unexpected faults may occur. For example, the task of removing scaffolding is interrelated with the task 
of casting concrete. If scaffolding were removed before the concrete had reached sufficient strength, there would be a risk of deflection or collapse. Therefore, both tasks need to be performed in careful consideration of their dependencies. Items interdependence disregard actions are mainly triggered by either rule-based or knowledgebased errors.

\subsection{Adoption of misguiding instruction ( $2 \%)$}

In contrast to instructions contravention where executors do not comply with the provided documents, adoption of misguiding instructions refers to embracing an instruction that is falsely presumed to guide defect-free construction (knowledge-based errors). Again, an instruction may be any detail included within an architectural drawing, structural drawing, MEP drawing, surveying report, lab recommendation, or any other source of construction guidance. However, instruction defects passed by any of these external bodies are not considered construction defects since they were committed by people other than those responsible for execution. Therefore, by establishing this category, we draw a separation line between defects committed by 'instructors' and those committed by 'executors'. Love and Josephson (2004) revealed that a portion of errors could have been prevented if information and instructions concerning the end product were rechecked on site prior to execution. For example, design or drafting defects are misguiding instructions that yield defects in construction when they are not detected by site managers (Assaf et al. 1995; Love, Josephson 2004). Thus, in the context of construction, we consider the adoption of these faulty instructions in itself a defective act. Further examples of adopting misguiding instructions include constructing footings on the basis of a faulty geotechnical lab recommendation (i.e. wrong foundation level), exceeding boundary limits due to an error in the surveyor's report or uncertain construction execution due to a discrepancy between architectural and structural drawings.

\section{Discussion: prevention of construction defects}

It was identified through data analysis that each defective act is associated with particular error types (skill-based, rule-based, knowledge based) or violations. Accordingly, results from this study imply that there are two main patterns of defective acts that Dubai residential construction industry suffers from most severely; namely, skill-based errors and violations. Skill based-errors are those characterized by poor workmanship (most occurring defective act) and deviations from intended dimensions (fourth most occurring defective action). Both are driven by the incompetence or inaccuracy of workers on site. Violations are, to a large extent, associated with the second, third and fifth most occurring defective acts: impaired material usages, task sequence omissions and instructions contraventions.

Poor workmanships and deviation from intended dimensions may be attributed to multiple factors. Commonly, the shortage of skilled labour supply compared with the increasingly high demand (Love et al. 2010d) compels builders to allocate workers with low levels of skill. Mackenzie et al. (2000) provides response strategies that employers and government decision makers in the UK construction industry may employ to address this problem. These are: i) to establish construction skills certification schemes managed by a trade union or a government body, so that only certified labourers are permitted to work on site; ii) to invest on increasing people skill standards by motivating companies in the industry to fund training and development for their staff; iii) to stabilize the economy within the industry; iv) to promote long term industry-wide training plans; v) to return to direct employment which ensures job retention, to increase effort toward training workers and workers' morale; and vi) the development of new construction technologies and techniques so that the industry depends less on workers, reducing the occurrence of human error. Nevertheless, besides the issue of workers, issues around incompetence and inaccuracy should also be attributed to managers, since quality control and assurance fall within their responsibility (Georgiou et al. 2000). For instance, Cross (2003, cited in Georgiou 2010) found that the systems used by builders, trades people and building inspectors have no recognized quality base. Cross also found that builders were not able to identify a method of quantifiably measuring and ensuring quality. This results in fluctuating quality standards among contractors in the industry. Thus, defect prevention strategies should be initiated by revising quality policies and procedures, toward developing measurable standards of workers' accuracy and workmanship.

Violations, on the other hand, are very difficult to manage. For instance, a three layer model proposed by Atkinson (1998) that shows the immediateness and the remoteness of factors contributing to a defect, suggests that actions directed at the primary causes will only have a partial, or no effect upon the elimination of deliberate violations. Nevertheless, some effective human resource practices may contribute towards reducing their occurrence since violations are mainly attributed to individuals' motivational problems (Reason 1995). Otherwise, workers neglect procedural tasks due to pressures imposed on them by the competitive environment in which they operate (Love et al. 2009). For this reason, training and good management practices (Gun 1993), as well as spreading awareness about the adverse effects of such violations, may be effective.

\section{Conclusions}

Understanding defects is a vital prerequisite to their prevention and elimination. Based on this principle, literature identifies various types of defective acts (i.e. slap, mistake, lapse and violation) and identifies some systems' root causes that stand as the basic reasons for defects. However, there is a need for more meaningful descriptions of the individualistic practices that are immediately and strictly linked to construction defects, whereas previous efforts were either generic to the industry as a while, or specific to design stages rather than the 
construction stage. The construction stage is by nature highly prone to errors since it involves a great deal of complexity and requires a high level of skill and professionalism. Construction is the stage where most instruction problems (e.g. design errors) are materialized, and therefore their mechanics can also be more comprehensively understood by addressing defective acts during construction. This paper therefore established a set classifications for defective acts encountered in Dubai's residential construction industry, in order to stimulate insights about the nature of defects suffered most severely by the industry, and their occurrence patterns. The underlying factors and conditions that trigger these defective acts vary.

Regardless of the triggers for these defects, the distinctive fact herein is that they all yield unacceptable or undesired results. The analysis of a sample of 272 instances suggests that a defect in the residential construction industry in Dubai could be triggered by any of the following defective acts: poor workmanship, impaired material usage, task sequence omission, deviation from an intended dimension, instructions contravention, professional principles/conventions noncompliance, official rule noncompliance, items interdependence disregard, adoption of misguiding instruction. Such classifications could be refined to fit other contexts such as commercial or industrial construction industries. In Dubai's residential construction industry, the most common categories of defective act was poor workmanship (20\%) and impaired materials usage $(20 \%)$. The following common types arose from task sequence omissions $(15 \%)$ followed by deviations from an intended dimension (13\%) and instructions contravention (10\%).

Results from this study imply that there are two main patterns of defects that the residential industry of Dubai most suffers from; these are mainly skill-based errors and violations. Skill-based errors are driven by the inaccuracy (e.g. deviation from an intended dimension) or the incompetency (e.g. poor workmanship) of workers. It is proposed that practitioners in the construction industry would benefit from a focus on developing strategies to enhance skill and professionalism among workers who execute construction work on site. Although violations are difficult to eliminate when cost and schedule pressures are imposed, project practitioners could strive to sustain the motivational human factors that can decrease their occurrence. Furthermore, this study implies that those defects that appear to be negligible to practitioners (i.e. poor workmanship) could prevent a large portion of construction problems (i.e. disputes) if eliminated.

A limitation of the method adopted in forming these classifications is that, although supported by explicit definitions of each defective act and the use of a flow chart to maintain as much reliable as possible, they were essentially based on the researchers' perceptions and judgments. Furthermore, since this study focuses on a specific context (Dubai residential construction industry in 2009), the study could be refined and extended to encompass a broad range of contexts. Despite this limitation, the defective act classifications are envisioned to bridge the missing link between root causes and the occurrence of a defect. Future research will focus on tracking the causal dynamics pattern of the provided defective act classifications, to specify what root causes account for their existence.

\section{References}

Abdelhamid, T.; Everett, J. 2000. Identifying root causes of construction accidents, Journal of Construction Engineering and Management 126(1): 52-60. http://dx.doi.org/10.1061/(ASCE)07339364(2000)126:1(52)

Abdul-Rahman, H. 1995. The cost of non-conformance during a highway project: a case study, Construction Management and Economics 13(1): 23-32. http://dx.doi.org/10.1080/01446199500000004

Alsadey, S.; Omran, A.; Pakir, A. 2010. Defects in the Libyan Construction Industry: a case study of Bani Walid City [oline], [cited 10 January 2011]. Available from Internet: http://acta.fih.upt.ro/pdf/2010-2/ACTA-2010-2-18.pdf

Aram, E.; Noble, D. 1999. Educating prospective managers in the complexity of organizational life, Management Learning 30(3): 321-342.

http://dx.doi.org/10.1177/1350507699303004

Ashford, J. L. 1992. The management of quality in construction. London: E \& F Spon. 252 p.

Assaf, S.; Al-Hammad, A.; Al-shihah, M. 1995. The effect of faulty construction on building maintenance, Building Research and Information 23(3): 175-181. http://dx.doi.org/10.1080/09613219508727452

Atkinson, A. R. 1998. Human error in the management of building projects, Construction Management and Economics 16(3): 339-349. http://dx.doi.org/10.1080/014461998372367

Bankvall, L.; Bygballe, E. L.; Dubois, A.; Jahre, M. 2010. Interdependence in Supply Chains and Projects in Construction, Supply Chain Management: An International Journal 15(5): 385-393.

Burati, J. S.; Farrington, J. J.; Ledbetter, W. B. 1992. Causes of quality deviations in design and construction, Journal of Construction Engineering Management 118(1): 34-49. http://dx.doi.org/10.1061/(ASCE)07339364(1992)118:1(34)

Busby, J. S. 2001. Error and distributed cognition in design, Design Studies 22(3): 233-254. http://dx.doi.org/10.1016/S0142-694X(00)00028-4

Busby, J. S.; Hughes, E. J. 2004. projects, pathogens and incubation periods, International Journal of Project Management 22(5): 425-434. http://dx.doi.org/10.1016/j.ijproman.2003.09.002

Chan, D. W. M.; Kumaraswamy, M. M. 1997. A comparative study of the causes of time and cost overruns in Hong Kong construction projects, International Journal of Project Management 15(1): 55-63. http://dx.doi.org/10.1016/S0263-7863(96)00039-7

CIDB. 1989. Managing Construction Quality, a CIDB manual on quality management systems for construction operations, Singapore.

Coles, E. J. 1990. Design management: a study of practice in the building industry, The Chartered Institute of Building, Occasional Paper, No. 42, UK, P.32. 
Cooper, K. G. 1993. The rework cycle: benchmarking for the project manager, Project Management Journal 24(1): 1722.

Crosby, P. B. 1984. Quality without tears: the art of hassle free management. New York, NY: McGraw-Hill. 205 p.

Georgiou, J. 2010. Construction management education, quality and housing [online], [cited 08 July 2011]. AUBEA 2010 Conference, Melbourne, Australia. Available from Internet: http://www.msd.unimelb.edu.au/events/conferences/ aubea2010/conference-papers/pdf/A090-Georgiou.pdf

Georgiou, J.; Love, P. E. D.; Smith, J. 2000. A review of builder registration in the State of Victoria, Australia, Structural Survey 18(1): 38-46.

http://dx.doi.org/10.1108/02630800010322526

Gidado, K. I. 1996. Project complexity: the focal point of construction production planning, Construction Management and Economics 14: 213-225.

http://dx.doi.org/10.1080/014461996373476

González, C. 2001. Caracterización de la Cultura Organizacional de la Construcción Nacional y su Influencia en Estrategias de Cambio [Characterization of The National Construction Organizational Culture and its Influence on Change Strategies]: MSc Thesis. Departamento de Ingeniería y Gestión de la Construcción, Pontificia Universidad Católica de Chile, Santiago.

Gun, R. T. 1993. The role of regulations in the prevention of occupational injury, Safety Science 16(1): 47-66. http://dx.doi.org/10.1016/0925-7535(93)90006-Y

Hammarlund, Y.; Josephson, P. E. 1990. Quality failure costs in building construction, in Proc. of CIB W55/W65 International Symposium at the University of Technology, Sydney, Australia.

Hammarlund, Y.; Josephson, P. E. 1991. Sources of quality failures in building, in Proc. of the European Symposium on Management, Quality and Economics in Housing and Other Building Sectors, 671-679.

Hammersley, M.; Atkinson, P. 1995. Ethnography: principles in practice. $2^{\text {nd }}$ ed. Tavistock: London. $275 \mathrm{p}$.

Homsma, G. J.; Van-Dyck, C.; De-Gilder, D.; Koopman, P. L.; Elfring, T. 2007. Overcoming errors: a closer look at the attributional mechanism, Journal of Business and Psychology 21(4): 559-583.

http://dx.doi.org/10.1007/s10869-007-9041-1

Josephson, P. E.; Hammarlund, Y. 1999. The causes of costs of defects in construction: a study of seven building projects, Automation in Construction 8(6): 681-687. http://dx.doi.org/10.1016/S0926-5805(98)00114-9

Kärnä, S. 2004. Analysing customer satisfaction and quality in construction - the case of public and private customers, Nordic Journal of Surveying and Real Estate Research, Special Series 2: 67-80.

Keltz, T. 1985. An engineer's view of human error. Institution of Chemical Engineers, Rugby, U.K.

Love, P. E. D. 2002. Auditing the indirect consequences of rework in construction: a case based approach, Managerial Auditing Journal 17(3): 138-146. http://dx.doi.org/10.1108/02686900210419921

Love, P. E. D.; Josephson, P.-E. 2004. Role of error-recovery process in projects, Journal of Management in Engineering 20(2): 70-79. http://dx.doi.org/10.1061/(ASCE)0742597X(2004)20:2(70)

Love, P. E. D.; Davis, P.; London, K.; Jasper, T. 2008. Causal modelling of construction disputes, in $24^{\text {th }}$ Annual
ARCOM Conference 2008, Association of Researchers in Construction Management, Reading, England, 869-878.

Love, P. E. D.; Edwards, D. J.; Irani, Z.; Walker, D. H. T. 2009. Project pathogens: the anatomy of omission errors in construction and resource engineering projects, IEEE Transactions on Engineering Management 56(3): 425-435. http://dx.doi.org/10.1109/TEM.2008.927774

Love, P.; Cheung, S.; Davis, P.; Ellis, J. 2010a. Dispute causation: identification of pathogenic influences in construction, Engineering, Construction and Architectural Management 17(4): 404-423. http://dx.doi.org/10.1108/09699981011056592

Love, P. E. D.; Cheung, S. O.; Irani, Z.; Davis, P. R. 2010 b. Causal discovery and inference of project disputes, IEEE Transactions on Engineering Management 58(3): 400411. http://dx.doi.org/10.1109/TEM.2010.2048907

Love, P. E. D.; Edwards, D. J.; Han, S. 2010c. Design error reduction: toward the effective utilization of building information modeling, Research in Engineering Design 22(3): 173-187. http://dx.doi.org/10.1007/s00163-011-0105-x

Love, P. E. D.; Edwards, D. J.; Watson, H.; Davis, P. 2010 d. Rework in civil infrastructure projects: determination of cost predictors, Journal of Construction Engineering and Management 136(3): 275-282.

http://dx.doi.org/10.1061/(ASCE)CO.1943-7862.0000136

Love, P. E. D.; Josephson, P. E. 2004. Role of error-recovery process in projects, Journal of Management in Engineering 20(2): 70-79. http://dx.doi.org/10.1061/(ASCE)0742597X(2004)20:2(70)

Mackenzie, S.; Kilpatrick, A. R. 2000. UK construction skills shortage response strategies and an analysis of industry perceptions, Journal of Construction Management and Economics 18(7): 853-862. http://dx.doi.org/10.1080/014461900433131

Malhotra, N.; Hall, J.; Shaw, M.; Oppenheim, P. 2002. Marketing research: an applied orientation. $2^{\text {nd }}$ ed. Prentice Hall, French Forests, NSW.

Mills, A.; Love, P. E. D.; Williams, P. 2009. Defect costs in residential construction, Journal of Construction Engineering and Management 135(1): 12-16. http://dx.doi.org/10.1061/(ASCE)0733-9364(2009)135: $1(12)$

Ortega, I.; Bisgaard, S. 2000. Quality improvement in the construction industry: three systematic approached, University of St. Gallen, Switzerland.

Pandey, B. H.; Okazaki, K.; Ando, S. 2008. Dissemination of earthquake resistant technologies for non-engineered construction, in The $14^{\text {th }}$ World Conference on Earthquake Engineering, Beijing, China, 12-17.

Perrow, C. 1984. Normal accidents - living with high-risk technologies. New York: Basic Books. $451 \mathrm{p}$.

Pressman, A. 1997. Professional practice 101: a compendium of business and management strategies in architecture. New York: John Wiley \& Sons. 345 p.

Rasmussen, J. 1983. Skills, rules, and knowledge: signals, signs, and symbols, and other distinctions in human performance models, IEEE Transactions on Systems, Man and Cybernetics 13(3): 257-266. http://dx.doi.org/10.1109/TSMC.1983.6313160

Reason, J. T. 1990. Human error. Cambridge, U.K.: Cambridge University Press. 302 p. http://dx.doi.org/10.1017/CBO9781139062367 
Reason, J. T. 1995. Understanding adverse events: human factors, Quality in Health Care 4(2): 80-89. http://dx.doi.org/10.1136/qshc.4.2.80

Reason, J. T. 1998. How necessary steps in a process get omitted: revising old ideas to combat a persistent problem, Cognitive Technology 3: 24-32.

Robson, C. 1993. Real world research: a resource for social scientists and practitioner-researchers. Blackwell, Oxford, U.K.

Rodrigues, A.; Bowers, J. 1996. The role of system dynamics in project management, International Journal of Project Management 14(4): 213-220. http://dx.doi.org/10.1016/0263-7863(95)00075-5

Serpell, A.; Ferrada, X. 2007. A competency-based model for construction supervisors in developing countries, Personnel Review 36(4): 585-602. http://dx.doi.org/10.1108/00483480710752812

Sommerville, J. 2007. Defects and rework in new build: an analysis of the phenomenon and drivers, Structural Survey 25(5): 391-407. http://dx.doi.org/10.1108/02630800710838437

Tilley, P. A.; McFallan, S. L. 2000. Design and documentation quality survey comparison of designers' and contractors' perspectives, BCE DOC 00/115, CSIRO Building, Construction and Engineering, Melbourne, Australia.
Van-Dyck, C.; Frese, M.; Baer, M.; Sonnentag, S. 2005. Organizational error management culture and its impact on performance: a two-study replication, Journal of Applied Psychology 90(6): 1228-1240. http://dx.doi.org/10.1037/0021-9010.90.6.1228

Waldron, B. D. 2006. Scope for improvement: survey of pressure points in Australian construction and infrastructure projects, a Report prepared for the Australian Constructors Association by Blake Dawson Waldron Lawyers, Sydney, Australia.

Watt, D. 1999. Building Pathology Principles and Practice. UK: Blackwell Science Ed. 277 p.

Williams, T. M. 2002. Modelling complex projects. Chichester: John Wiley and Sons. 288 p.

Willis, T. H.; Willis, W. D. 1996. A quality performance management system for industrial and construction engineering projects, International Journal of Quality \& Reliability Management 13(9): 38-48. http://dx.doi.org/10.1108/02656719610150605

Winch, G. M. 2003. Models of manufacturing and the construction process: the genesis of re-engineering construction, Building Research and Information 31(2): 107-118. http://dx.doi.org/10.1080/09613210301995

Hamad A. ALJASSMI received the Bachelor of Science in Civil Engineering degree from the University of Greenwich, UK in 2007, and the Master of Business Administration from the University of Cardiff, UK in 2008. He is currently a PhD candidate in the School of Civil and Environmental Engineering, University of New South Wales, Australia. His research interests include defects in construction projects.

Sangwon HAN is an Assistant Professor of the Department of Architectural Engineering at the University of Seoul, Seoul, Korea. Before joining the University of Seoul, he worked as a Lecturer for the School of Civil and Environmental Engineering at the University of New South Wales, Sydney, Australia. He is an Associate Editor of the Journal of Construction Engineering and Project Management. His research interests include construction project simulation, lean construction, building information modeling, and sustainable construction. 